\title{
The ABCs of managing increased intracranial pressure
}

\author{
Mohamed Toufic EL Hussein *' Stephanie Zettel, Ashley M. Suykens \\ School of Nursing and Midwifery, Mount Royal University, Canada
}

Received: June 24, 2016

DOI: $10.5430 /$ jnep.v7n4p6
Accepted: October 23, 2016

Online Published: November 14, 2016

URL: http://dx.doi.org/10.5430/jnep.v7n4p6

\begin{abstract}
Increased intracranial pressure is a complex condition that could pose challenges to the novice practitioner. The authors of this manuscript established a mean of explaining how to care for a patient with elevated intracranial pressure in the form of a mnemonic. The alphabetical mnemonic is based on the key points of interest that address important aspects for caring for a patient with increased intracranial pressure. This paper highlights an innovative approach of piecing together the mosaic of intracranial pressure for students and novice practitioners. The alphabetical mnemonic is further summarized in a table outlining the assessment of the patient, the nursing strategy, and when action is required. The mnemonic presented allows the practitioner or student to readily remember and recognize how to care for a patient with increased intracranial pressure.
\end{abstract}

Key Words: Increased intracranial pressure, Novice practitioner, Alphabetical mnemonic

\section{Aims AND InTENDED LEARning OUT- COMES}

The authors of this article aim to provide an overview of how to manage increased intracranial pressure by using an alphabetical mnemonic that starts with $\mathrm{A}$ and ends with $\mathrm{L}$. Identified through the mnemonic are nursing strategies and interventions that address potential clinical problems in patients with increased intracranial pressure (ICP). After reading this article you should be able to:

- Have a basic knowledge of why elevated ICP is so complex;

- Discuss the nurse's role in managing increased intracranial pressure;

- Apply the mnemonic when planning evidence-based care for a patient with increased intracranial pressure.

\section{INTRODUCTION AND CONTEXT}

Understanding the complexities of nursing care management of an individual with increased ICP is essential for patients' safety and students' learning. The concomitant failure of multiple body systems and how they affect one another can be overwhelming for the novice practitioner. The authors of this manuscript felt the need to develop a method by which students could understand the nuances of nursing care, incorporating the social determinants of health and appreciating the implications of nursing care in the larger health care system.

According to March \& Hickey (2014) changes in ICP can be very rapid and require a rapid response from the nurses. ${ }^{[1]}$ Increased ICP calls for a rapid response on behalf of the nurse, essentially because ischemic brain cells start dying 4-6 minutes after the cessation of blood supply. ${ }^{[2]}$ About 5 to 10 minutes of complete occlusion is necessary for irreversible brain damage in humans. As brain cells start to die, a myriad cellular processes are initiated that result in brain cells edema, mainly because ATP is no longer produced and is not able to fuel the ion pumps that maintain the integrity of the cell membrane. As a result cerebral edema and in-

\footnotetext{
*Correspondence: Mohamed Toufic EL Hussein; Email: melhussein@mtroyal.ca; Address: School of Nursing and Midwifery, Mount Royal University, Canada.
} 
creased ICP will ensue. Normal ICP is approximately 0-10 $\mathrm{mmHg}$, although $15 \mathrm{mmHg}$ is considered the upper limit of normal. ${ }^{[1]}$

The skull is a rigid compartment filled to its maximum capacity and is established by the volumes occupied by the brain (80\%), blood (10\%), and cerebrospinal fluid (CSF) (10\%). ${ }^{[2]}$ According to Monroe-Kellie hypothesis these 3 volumes generate a pressure inside the cranium that is referred to as ICP. The ICP is kept within normal range due to the brain's ability to either constrict cerebral arterioles leading to decrease cerebral blood volume or increase the absorption of CSF leading to decrease in cerebral CSF. Monroe-Kellie hypothesis delineates the relationships between the compensatory responses of the brain when the ICP increases. It depicts the relationship between ICP, mean arterial pressure (MAP) and cerebral perfusion pressure $(\mathrm{CPP})$ as:

$\mathrm{CPP}=\mathrm{MAP}-\mathrm{ICP}$ where MAP $=$ Systolic $\mathrm{BP}+2 \times$ Diastolic $\mathrm{BP} / 3 .^{[3]}$

The CPP must be at least $60 \mathrm{mmHg}$ to adequately perfuse the brain with blood. ${ }^{[3]}$ In other words, as a space-occupying lesion, such as a hematoma or neoplasm expands it puts pressure on the brain and the ICP will increase. This increase in ICP stimulates the autoregulatory mechanisms in order to compensate and lower ICP, namely the reabsorption of CSF by the arachnoid villi and the reactive vasoconstriction of cerebral arterioles. ${ }^{[3]}$ As the brain loses the ability to autoregulate its response to increased ICP (i.e. the hematoma or neoplasm is not evacuated and/or is growing), the sympathetic nervous system is stimulated to increase the systolic blood pressure and consequently the MAP, in order to maintain adequate CPP. This is known as the Cushing's reflex. ${ }^{[2]}$

\section{EFFECTS OF BLOOD GASSES ON ICP}

The reticular activating system is a neural structure responsible for the wakefulness state and is very sensitive to changes in the partial pressure of oxygen in arterial blood. The reticular activating system traverses the brain stem to reach the thalamus. ${ }^{[2]}$

Both an increase in ICP and or a decrease in CPP, can result in decrease partial pressure of oxygen in arterial blood resulting in altered level of consciousness (LOC) ${ }^{[2]}$ Increasing partial pressures of carbon dioxide in arterial blood results in vasodilation and activation of the respiratory center to hyperventilate and breathe off more $\mathrm{CO}_{2} \cdot{ }^{[3]}$ Cushing's triad is the presentation of 3 clinical manifestations as they relate to decompensated responses to increasing ICP: widening pulse pressure with hypertension (increasing systolic $\mathrm{BP}$ ), bradycardia, and irregular respirations (most commonly, bradypnea).

Published by Sciedu Press
Using the alphabetical mnemonic for nursing care has greatly improved both our teaching of the material, as well as the students' retention and application of it. Students are able to make connections of what they are learning to what they already know and are able to rely on retrieval of cues that are essentially common to almost everyone using the traditional alphabet. Understanding basic concepts in this way creates a schema by which students come to apply this acronym to novel clinical situations. Examples from our own practice also provide some context in how knowing the ABCs fosters competent nursing care of the patient with increased ICP.

\section{THE ABCS OF ICP}

A: Airway. A is for airway. ${ }^{[4]}$ Maintenance of a patent airway is essential for preventing hypoventilation, which can result in hypoxemia and hypercapnia (hypercarbia) due to increased alveolar $\mathrm{CO}_{2}$ which displaces oxygen, further increasing ICP by causing vasodilation of cerebral blood vessels. ${ }^{[2]}$ Increasing ICP puts pressure on the cranial nerves altering their function. According to Banasik (2013), all cranial nerves originate in the brainstem except cranial nerves I and II, which originate in the diencephalon. ${ }^{[5]}$ Pressure on the glossopharyngeal, vagus and hypoglossal nerves (cranial nerves IX, X and XII) in particular impact the patient's ability to swallow and control their tongue, such that the airway can become blocked with either secretions or the tongue itself. Intubation is important in order to prevent hypoxemia. The patient is connected to a mechanical ventilator by which inhalation and exhalation pressures can be controlled. This is in order to minimize the partial pressure of $\mathrm{CO}_{2}$ in the blood, blood volume in the brain (since $\mathrm{CO}_{2}$ causes vasodilation) and the resultant increase in ICP. ${ }^{[3]}$ Neural control of the respiratory system is located in the medulla oblongata and the pons, which is commonly referred to as the respiratory center. Efferent nerve impulses travel from the brainstem by the way of phrenic nerve to the diaphragm to stimulate muscular contraction for inspiration. ${ }^{[6]}$ Hence, pressure on the brainstem can impede the normal function of the respiratory center.

Maintaining the airway is also essential, for ATP production is dependent on a continuous oxygen supply. An inadequate supply of cellular ATP inhibits energy-dependent cellular functions, due to hypoxemia maintenance of ion concentration across the plasma membrane. ${ }^{[2]}$ Because of their steep electrochemical gradients, extracellular sodium and calcium ions tend to leak into the cell. ATP-dependent pumps in the cell membrane are needed to continuously pump these ions back out. Failure of the ion pumps leads to sodium and water accumulation in the cell and an excess of intracellular free calcium. Intracellular calcium ions trigger a cascade 
of events that impair plasma membrane integrity leading to ischemic or dead brain cells.

B: Blood Pressure. Maintaining an adequate blood pressure to ensure a cerebral perfusion can be quite challenging in the context of increasing ICP. As mentioned previously, when allostatic mechanisms no longer function to bring about homeostasis, the systolic BP will rise due to the Cushing's reflex and increased sympathetic innervation designed to overcome the increased resistance to cerebral blood flow created by the increased ICP ${ }^{[3]}$ This sympathetic response occurs because normal autoregulatory mechanisms at the level of the blood vessel or vasodilation in response to chemical mediators such as $\mathrm{CO}_{2}$, are no longer effective in maintaining fluid balance. The body's resources are mobilized in a typically short-lived response. ${ }^{[2]}$

Aggressive control of a patient's BP can often lead to a suboptimal CPP because this also decreases the MAP. ${ }^{[7]}$ Recalling the Monroe-Kellie Hypothesis, namely CPP = MAP - ICP, nursing care focuses on achieving a BP that is not too high, yet is high enough to overcome the resistance created by the increased ICP. This narrow range is also necessary in order to minimize the increased demand for oxygen and nutrients that come with the sympathetic response, as well as optimize cardiac output and consequently, cerebral perfusion pressure. ${ }^{[7]}$ Blood pressure is usually managed via three mechanisms: the judicious administration of IV fluid, which provides enough blood volume and increased cardiac output; a balance of inotropes (such as dobutamine); and mixed alpha1/beta1blockers (such as labetolol). Inotropes stimulate contractility and maintain cardiac output by increasing the force of contraction, whereas mixed alpha1/beta1-blockers minimize the resistance that the heart has to pump against by causing vasodilation in the blood vessels and blocking sympathetic stimulation to the heart. ${ }^{[8]}$

C: Cervical Collar. Brain injury and spinal cord injury often occur together due to the nature and mechanism of injury. For instance, a patient involved in a motor vehicle crash might experience a coup-contre-coup injury with contusions on both the frontal and occipital areas of the brain, as well as a simultaneous flexion and extension injury of the neck. A cervical collar is applied to immobilize the neck and prevent spinal cord injury. It also is used to avoid any flexion of the neck, which could inadvertently prevent venous outflow from the head, causing an increase in ICP. ${ }^{[7]}$ Applying a cervical collar is standard practice when any trauma to the head or neck occurs. However, cervical collar placement has also been shown to increase intracranial pressure if not applied correctly. ${ }^{[9]}$ This is due to its potential to increase intracranial blood volume as drainage of venous blood flow is impaired because of the increased pressure on the neck by the cervical collar. Thus, a cervical collar may act like a tourniquet on the jugular veins. The pressure of the cervical collar may also increase respiratory effort, hindering effective airway management. As noted above, maintenance of a patent airway is essential to prevent any further increase in ICP. A third risk factor associated with cervical collars is skin breakdown, most concerning an occipital pressure ulcer. Any iatrogenic conditions can further delay the recovery of the patient, and thus should be avoided at all costs.

C: Calm. Increased ICP is a result of stress on the body and continued sympathetic stimulation, causing oxygen and nutrient demand to outweigh supply. Nursing care for the patient with increased ICP is calm, and not rushed. Clustering nursing care or patient activities increases the patient's metabolism, the production of $\mathrm{CO}_{2}$, and causes vasodilation of cerebral vessels, thus increasing ICP. ${ }^{[3]}$ The focus of nursing care is on decreasing stimulation of the patient and decreasing their stress. This is done by providing a darkened room, decreasing noise, minimizing visitors and minimizing nursing tasks such as suctioning. Practitioners are only to do patient tasks when absolutely necessary. Patients might even be chemically paralyzed (i.e. by barbiturates) and intubated in order to minimize the requirements for their metabolism. The comatose state of the patient protects the brain by minimizing the metabolic demand of the brain, and thus decreasing ICP.

D: Decompression of the Stomach. Why decompress the stomach? Clinical reasoning for this course of action is based on facilitating venous outflow of blood from the head. This is commonly done with the insertion of an orogastric (OG) or nasogastric (NG) tube that is connected to intermittent or continuous suction. Reducing pressure within the gastrointestinal (GI) tract by removing gastric contents via suction decreases intraabdominal pressure allowing effective contraction of the diaphragm (i.e. flattening), increasing volume in the thoracic cavity thus decreasing intrathoracic pressure and facilitating maximum expansion of lungs leading to better ventilation. The decrease in intrathoracic pressure allows for better draining of the jugular veins into the right atrium, thus preventing venous congestion in the cerebral veins and a potential increase in ICP.

Patients with basal skull fractures are more complicated because of the potential for infection and further trauma. ${ }^{[2]}$ Basilar skull fractures are located at the base of the cranium. Basilar skull fracture can be difficult to detect with routine radiographic studies. ${ }^{[10]} \mathrm{CSF}$ and blood may leak out of the nose and ears, and ecchymosis is evident at the mastoid process (Battle's sign) and in the ocular orbits, giving patients 
a raccoon eye appearance. Rhinorrhea is positive for glucose and leaves a halo effect on gauze dressing if it is CSF. In this case, insertion of a NG tube is contraindicated, and an OG tube indicated, because of the potential for the NG tube to cause direct damage to the brain, causing even more complications. ${ }^{[7]}$

D: Dim the Lights. Dimming the lights aids with keeping the patient calm, by reducing the metabolic demand of the patient and decreasing their level of stress. A darkened room minimizes the stimulation caused by light, leading to a more tranquil environment. Similar to how most people can fall asleep easier when the lights are dimmed, dimmed lights facilitate this same relaxed response in patients with increased ICP. Rest is vital for a patient recovery, and a darkened room allows the patient to have a less disrupted sleep. ${ }^{[7]}$

E: Edema. As blood flow to the brain is compromised, brain cells become ischemic and begin to die. ${ }^{[3]}$ Edema is related to two mechanisms, vasoactive and cytotoxic edema. Vasoactive edema occurs because of the increased permeability of the cell membrane caused by the build-up of waste products, such as $\mathrm{CO}_{2}$. These waste products have a direct vasodilatory effect on the blood vessels of the brain, and fluid moves from the vascular space into the interstitial space, causing edema.

Cytotoxic edema is related to the failure of the sodiumpotassium pumps. ${ }^{[2]}$ The sodium-potassium pumps are fueled by ATP, and because ATP production is dependent on a continuous oxygen supply, these pumps begin to malfunction. The purpose of these pumps is to maintain the electrochemical gradient by pumping sodium back to the extracellular space and potassium back inside the cell. As these pumps begin to fail, sodium remains inside the cell and pulls water with it (due to osmosis) resulting in hydropic swelling. Cellular organelles such as the mitochondria, are not able to generate ATP, and this begins to affect cellular processes inside the cell that rely on calcium. Calcium is not sequestered back to the sarcoplasmic reticulum and accumulates inside the cell causing cell apoptosis.

Assessment of cerebral edema necessitates an understanding of the cranial nerves and fluid balance (which will be discussed later in this paper).

E: Elevate the Head. Raising the head of the bed to 30 degrees facilitates venous outflow from the brain via gravity. ${ }^{[1]}$ Elevation of the head lowers ICP via two mechanisms. First, it promotes drainage of the jugular veins, and thus drainage of the veins in the brain. ${ }^{[1]}$ Secondly, an elevated head of the bed promotes CSF to drain into the spinal canal, decreasing the amount of CSF in the brain. It is important to note, that in order for the nurse to elevate the head of the bed to 30 degrees, the patient must not be hypovolemic.

E: Eyes. The eyes are the windows to the brain; they are controlled by many cranial nerves which are easily compressed with cerebral edema. ${ }^{[2]}$ The cranial nerves are numbered according to where they are in the brain. Only the olfactory and optic nerves (cranial nerves I and II) derive from the diencephalon, whereas cranial nerves III-XII are attached to the brain stem. ${ }^{[5]}$ With increasing cerebral edema, it is the first cranial nerve coming off the brain stem that is most often compromised. This is the oculomotor nerve and is responsible for the constriction and dilation of the pupil. ${ }^{[2]}$ When this nerve is compressed, the pupil will become dilated and less reactive to light. Tentorium herniation of the brain will result in a fixed and dilated pupil on the ipsilateral side of the hematoma or neoplasm.

Making the diagnosis of brain death for someone with increased ICP for any practitioner is difficult because of the ethical implications this has for patient care (these will be discussed later in the paper). The diagnosis of brain death is made easier through assessment of the cranial nerves. The oculovestibular reflex, or the doll's eye reflex, can be elicited by turning the head from side to side while holding open the patient's eyelids. ${ }^{[2]}$ As the head is turned in one direction, the eyes should turn in the opposite direction. If the head is turned to the right, the patient's gaze should turn to the left and vice versa. In someone who is brain dead, this reflex is not intact, and the eyes follow the movement of the head. If cervical spine protection is a concern, this same reflex can be tested by pouring cold water into the ear and assessing the direction of the eye movement, or nystagmus. Cold water in the ear (cold caloric reflex normally) results in ipsilateral nystagmus, whereas warm water in the ear (warm caloric reflex) results in contralateral nystagmus. Similarly, the corneal reflex can be tested by using a wisp of cotton and lightly brushing the cornea of the eye. If this reflex is intact, patients should normally blink in response to this stimulation. Hence, the eyes are a way that practitioners can look into the patient's brain, in order to make the diagnosis of brain death.

F: Fluids and Electrolytes. Management of fluids and electrolytes is complex with increasing ICP. Compression of the hypothalamus affects regulation of fluid status through the posterior pituitary gland and antidiuretic hormone (ADH) ${ }^{[3]}$ Patients can present with diabetes insipidus (decreased ADH) and large amounts of dilute urine, as well as syndrome of inappropriate production of antidiuretic hormone (SIADH) (increased $\mathrm{ADH}$ ) and concentrated urine. The urine of patients with increasing ICP is tested for specific gravity. A low specific gravity indicates dilute urine with decreased production of $\mathrm{ADH}$, and a high specific gravity indicates more 
concentrated urine and greater water reabsorption. Antidiuretic hormone functions in the distal tubule and collecting duct of the nephron to increase the absorption of water. The concentration of electrolytes is greatly impacted with these changes in ADH. Sodium is the primary extracellular electrolyte, and hypo- and hypernatremia can result in seizures and a secondary brain injury. ${ }^{[11]}$

A hypertonic IV solution of $3 \%$ sodium chloride is often administered to pull fluid from swollen brain cells into the vascular space so that it can be eliminated by the kidneys. ${ }^{[3]}$ Likewise, mannitol can be administered IV. Mannitol is an osmotic diuretic which also draws fluid into the vascular space via osmosis, because of the greater concentration of solute particles in the solution. Mannitol does not cross the tight junctions of the blood brain barrier, and as such, is an ideal solution to give in the context of increased ICP. ${ }^{[12]}$ Fluid moves from swollen brain cells into the vascular space so that it may be eliminated by the kidneys. The nature of osmotic diuretics is that they work by exerting their osmotic effect everywhere in the body; mannitol in the vascular space increases blood volume, cardiac output and renal blood flow, and mannitol in the nephron pulls water into the urine filtrate so that it may be eliminated by the kidney. Because of these massive fluid shifts, patients can exhibit a wide variety of fluid and electrolyte imbalances: fluid overload (as water moves to the vascular space and puts pressure on the heart by increasing preload) to dehydration (as water is drawn into the urine filtrate and eliminated from the kidney). Hypoand hypernatremia, as well as hypo- and hyperkalemia are common occurrences and can be life-threatening. Similarly, mannitol is contraindicated with someone exhibiting heart failure or kidney disease.

F: Food. The stimulation of the sympathetic nervous system in response to increased ICP requires oxygen and nutrients. Patients are in a hypermetabolic state; they require nutrients and oxygen in order to fuel the ATP processes of the cell and maintain the electrochemical gradient of the cell membrane. ${ }^{[7]}$ Compression of the glossopharyngeal, vagus and hypoglossal nerves (cranial nerves IX, X and XII) can result in impaired swallowing, taste and movement of food in the mouth. ${ }^{[5]}$ Furthermore, damage to the trigeminal nerve (cranial nerve $\mathrm{V}$ ) can result in impaired chewing and sensation of food in the mouth. Because of this, patients are a high aspiration risk. Before administering anything orally, a speech pathologist should be consulted.

A high calorie, high protein and often high fiber, because of decreased stimulation to the GI tract, diet is initiated. A tube feed is inserted to provide nutrition via a NG tube, an OG tube, or directly into the stomach through a percuta- neous endoscopic gastrostomy (PEG) tube once patients are stabilized. ${ }^{[7]}$

F: Family. The prognosis of complications from increased ICP is poor. Once the diagnosis of brain death is made, it is a nursing responsibility to provide supportive care for the family. ${ }^{[7]}$ Nurses have the ethical responsibility to provide all the facts, ensuring that families are making decisions on advanced care planning based on all the information that is available to them, as well as competent and knowledgeable assessment and analysis of the patient's condition. Nurses are in a prime position to initiate and follow through with advanced care planning, collaborate with other members of the multidisciplinary team in order to validate the position of the family and involve the family in all aspects of care. Nurses may suggest the family to support groups, grief counsellors, organ procurement team members, and to external resources such as The Brain Injury Association. These resources aid the family in coping with the loss of their loved one.

G: Glasgow Coma Scale. The Glasgow Coma Scale (GCS) is a universal scale with consistent reliability that measures LOC based on the patient's ability to open their eyes, their motor function and their verbal behavior. ${ }^{[2]}$ The monitoring of one's LOC is vital because changes in LOC precede changes in other vital and neurologic signs. Patients are scored from 1-4 for eye opening, where a score of 4 means that they are able to open their eyes spontaneously and a score of 1 indicates no response. The verbal score is out of 5 , where a score of 5 indicates normal conversation and progresses to incomprehensible sounds (2/5), to no response (1/5). Finally, the motor response is scored out of 6 where a score of 6/6 indicates normal function, 5/6 indicate localizing pain, and $4 / 6$ means the patient is withdrawing to pain. A score of $3 / 6$ means that the patient is exhibiting signs of decorticate posturing, meaning there is flexion of the elbows and extension of the legs. As ICP rises and impairs the functioning of the brain stem, posturing progresses to the decerebrate type (2/5). As basic body processes like breathing and circulation become impaired, the arms extend with flexion of the wrists and extension of the legs. Flaccidity is a score of $1 / 5$ on the GCS. The highest score is 15 , and the lowest 3. A score between 8-3 is considered to indicate a severe brain injury. Ongoing monitoring of LOC using the GCS is imperative for correcting any changes in ICP as soon as possible.

H: Hyperventilate. Controlled hyperventilation lowers the partial pressure of $\mathrm{CO}_{2}$ in arterial blood $\left(\mathrm{PaCO}_{2}\right)$ and increases the $\mathrm{pH}$ in order to minimize vasodilation of cerebral blood vessels. ${ }^{[3]}$ The increased partial pressures of oxygen in arterial blood $\left(\mathrm{PaO}_{2}\right)$ cause vasoconstriction and decrease 
cerebral blood flow. This, in turn, decreases ICP. When hyperventilation goes unchecked, however, vasoconstriction of cerebral blood vessels can result in inadequate cerebral blood flow to the tissues, and worsen the patient's condition. ${ }^{[2]}$ Hyperventilation must be maintained with a CPP of at least $60 \mathrm{mmHg}$ in order to be effective at decreasing ICP. ${ }^{[3]}$ Hyperventilation therapy is used only on a patient to patient basis, and only when considered appropriate. Constant monitoring of the $\mathrm{PaCO}_{2}$ is crucial.

H: Hyperthermia. Hyperthermia increases the metabolic requirements of the brain and also increases the level of $\mathrm{CO}_{2}$ in the body; thus, prevention of hyperthermia is key for patients with increased ICP. ${ }^{[3]}$ An increase in body temperature may indicate brain stem damage and is a poor prognostic sign. ${ }^{[7]}$ Managing hyperthermia is done via inducing moderate hypothermia, and is often accomplished by nursing interventions, such as providing patients with cooling blankets and cooling their core body temperatures to $32^{\circ} \mathrm{C}-34^{\circ} \mathrm{C}$, essentially putting them into a sort of hibernation. This limits continued ischemia of the brain cells by causing vasoconstriction of cerebral blood vessels, and decreasing oxygen and nutrient demands. Limiting metabolic requirements is also addressed with the administration of neuromuscular blockers like rocuronium and sedatives like midazolam. Induced hypothermia should occur after 2-6 hours of injury onset, and for a minimum of two days. The rewarming of the patient must be gradual to prevent any further brain damage. ${ }^{[13]} \mathrm{A}$ rapid rewarming counteracts the benefits of maintained hypothermia because reperfusion injuries could occur. Thus, a practitioner must monitor a patient's body temperature and watch for any subsequent increases in ICP if induced hypothermia is used.

H: Hip Flexion. Hip flexion in a patient with elevated ICP should be avoided at all times. ${ }^{[1]}$ Flexion of the hips puts pressure on the abdominal cavity, which leads to increased intrathoracic pressure. Because the jugular veins that drain the brain are valveless, heightened intrathoracic pressure inhibits venous drainage from the brain. This adds to increased ICP, due to inhibition of venous outflow from the brain. Prevention of hip flexion is especially critical when the head of the bed is elevated. It is a nurse's duty to ensure that the body is laterally aligned.

Isometric muscle contractions, such as hip flexion against resistance, is another causation of ICP increase. For instance, if a patient is to push against the bed with their feet, they are performing an isometric muscle contraction. These types of muscle movements cause systemic blood pressure to increase, and thus cause a rise in ICP as well. Other examples of isometric movements are decortication and decerebration positions.

H: Herniation. Herniation of the brain refers to the protrusion of brain tissue through the dura mater. ${ }^{[2]}$ This causes irreversible brain death. ${ }^{[3]}$ A great increase in ICP causes an abundance of pressure in the intracranial space, causing compression and interruption of blood flow to the brain stem, and brain death. There are several types of brain herniation, differentiated via their location. Subfalcine herniation carries a better prognosis than most, and can be asymptomatic. ${ }^{[2]}$ Brain death within minutes occurs with tonsillar herniation. Tentorial herniation is of two types, bilateral (causing central transtentorial herniation) and lateral (where herniation occurs through the tentorial opening). They are associated with intracranial hypertension, and may exacerbate ischemia by initiating CSF obstruction and vascular obstruction.

I: ICP monitoring. Measured in the lateral ventricles of the brain, the normal values of ICP are 0 to $10 \mathrm{mmHg}$, with $15 \mathrm{mmHg}$ being the upper limit of normal. ${ }^{[3]}$ Any pressure greater is considered to be increased. Pivotal to the care of a patient with increased ICP is careful observation and assessment of neurological function; this should be done early in the course of the diagnosis of increased ICP, for the patients prognosis is greatly improved. The reasons for doing so are plentiful. Quantifying the degree of ICP elevation in order to initiate treatment and to evaluate how effective the treatment is, to gain access to the CSF for sampling and for draining, as well as to identify changes in ICP, which is an indicator of the patient's condition. ${ }^{[3]}$

ICP monitoring is done directly via a catheter inserted into a hole in the skull (burr hole). ${ }^{[2]}$ The pressure exerted by the fluid in the catheter is measured as electrical impulses and is reflected on a digital monitor. The electrical impulses are seen on an oscilloscope by the practitioner in the form of waves. Waves of high pressure and troughs indicating normal pressure express changes in ICP. ${ }^{[3]}$ There are three types of waves, A waves, B waves, and C waves. A waves, or plateau waves, have clinical significance because they depict changes of vascular volume within the intracranial compartment that are compromising cerebral perfusion. They last from 5-20 minutes, and vary in amplitude from 50-100 $\mathrm{mmHg}$. These waves present brain damage before clinical signs and symptoms can be seen. B waves are shorter and of smaller amplitude (lasting up to 2 minutes and reach up to $50 \mathrm{mmHg}$ ), and they precede $\mathrm{A}$ waves. The clinical significance of $\mathrm{C}$ waves is unknown, however they are rhythmic oscillations that appear to be related to systematic arterial blood pressure and respirations. 
Table 1. The ABCs of managing increased intracranial pressure

\begin{tabular}{|c|c|c|c|}
\hline & $\begin{array}{l}\text { Patient } \\
\text { Assessment }\end{array}$ & Nursing Strategy & Action Required \\
\hline A & Airway & $\begin{array}{l}\text { To maintain the airway, the patient is intubated. Monitor level of consciousness via the Glascow } \\
\text { Coma Scale (GCS). }\end{array}$ & $\begin{array}{l}\text { Airway maintenance is crucial for } \\
\text { prevention of hypoxemia and hypercapnia, } \\
\text { which further increases ICP. }\end{array}$ \\
\hline B & Blood Pressure & $\begin{array}{l}\text { Controlling BP must be done carefully because CPP= MAP-ICP } \\
\mathrm{BP} \text { is managed } 3 \text { ways: IV fluids, Inotropes, Mixed alpha } \text { /beta }_{1} \text {-blockers. }\end{array}$ & $\begin{array}{l}\text { Blood pressure control is used to help } \\
\text { decrease ICP, by maintaining an adequate } \\
\text { cerebral perfusion pressure. } \\
\text { The Cushing's Reflex requires BP } \\
\text { management, to help counteract the rise in } \\
\text { systolic blood pressure. }\end{array}$ \\
\hline C & $\begin{array}{l}\text { I) Cervical } \\
\text { Collar } \\
\text { II) Calm }\end{array}$ & $\begin{array}{l}\text { I) A cervical collar is applied to the patients neck to immobilize it. Risk of increasing ICP further, } \\
\text { skin breakdown, or impeding airway. } \\
\text { II) Nurses remain calm when caring for a patient with elevated ICP. Clustering activities is } \\
\text { avoided to prevent the patient from becoming stressed. Decreasing stimulation by minimizing } \\
\text { noise, turning off the lights, and only doing necessary nursing interventions decreases the stress } \\
\text { the patient feels as well. Patient may also be chemically paralyzed or sedated. }\end{array}$ & $\begin{array}{l}\text { I) Cervical collar is applied anytime neck } \\
\text { or head trauma is suspected } \\
\text { II) Patient should always be kept calm, } \\
\text { especially if they are stressed or agitated, } \\
\text { which results in continuous sympathetic } \\
\text { stimulation, and a rise in ICP. }\end{array}$ \\
\hline D & $\begin{array}{l}\text { I) } \\
\text { Decompression } \\
\text { II) Dim Lights }\end{array}$ & $\begin{array}{l}\text { I) Insertion of an NG or OG tube connected to suction, to drain GI contents allows for } \\
\text { decompression of the stomach. NG tubes are contraindicated with basilar skull fractures. } \\
\text { II) Nurses can dim the lights in the patient's room in order to minimize the stimulation caused by } \\
\text { light, relaxing the patient and promoting rest. }\end{array}$ & $\begin{array}{l}\text { I) Decompression is done to decrease the } \\
\text { pressure in the GI that leads to decreased } \\
\text { intrathoracic pressure, which facilitates } \\
\text { expansion of the lungs and venous outflow } \\
\text { from the head. } \\
\text { II) The lights are dimmed when the patient } \\
\text { requires rest, is anxious or stressed, for it } \\
\text { helps to reduce their metabolic demand. }\end{array}$ \\
\hline $\mathbf{E}$ & $\begin{array}{l}\text { I) Edema } \\
\text { II) Elevate } \\
\text { Head of Bed } \\
\text { III) Eyes }\end{array}$ & $\begin{array}{l}\text { I) Assess cerebral edema in relation to cranial nerve function. This is done by assessing the } \\
\text { response of the eyes, as discussed further on. } \\
\text { II) Head of the bed should be elevated to } 30 \text { degrees to facilitate venous outflow from the brain. } \\
\text { III) There are multiple assessments a practitioner can perform in order to assess the eyes: } \\
\text { - Oculomotor nerve- when nerve is constricted, the pupil becomes dilated and less reactive to light. } \\
\text { Tentorial Herniation of the brain is also diagnosed via this nerve, when the eyes become fixed and } \\
\text { dilated. } \\
\text { - Oculovestibular reflex/ Doll's eye reflex- patient's head is turned side to side while holding up } \\
\text { the eyelids. If the head is turned left, the eyes should turn right and vice versa. If this does not } \\
\text { happen, the diagnosis of brain death is concluded. } \\
\text { - Cold/warm caloric reflex- used to diagnose brain death if cervical spine protection is a concern. } \\
\text { This is done by pouring warm or cold water into the ear and observing the movement of the eyes. } \\
\text { With cold water, the eyes result in ipsilateral nystagmus, whereas warm water the eyes move via } \\
\text { contralateral nystagmus. } \\
\text { - Corneal reflex- a wisp of cotton is lightly brushed against the cornea; the patient should blink. }\end{array}$ & $\begin{array}{l}\text { I) Assessment is done to evaluate the } \\
\text { degree of compression of the brain } \\
\text { structures, and thus the amount of } \\
\text { ischemia suspected. } \\
\text { II) Head of bed is elevated to avoid an } \\
\text { increase in ICP. Head of bed placed flat } \\
15-30 \text { minutes before a patient goes for a } \\
\text { CT or MRI. } \\
\text { III) Assessment of the eyes is an indicator } \\
\text { of the amount of cerebral edema present. } \\
\text { The more edema, the more compressed the } \\
\text { brain stem, hence where cranial nerves III } \\
\text { to XII originate. This assessment is also } \\
\text { done to aid in the diagnosis of brain death. }\end{array}$ \\
\hline $\mathbf{F}$ & $\begin{array}{l}\text { I) Fluid and } \\
\text { Electrolytes } \\
\text { II) Food } \\
\text { III) Family }\end{array}$ & $\begin{array}{l}\text { I) Monitoring fluids and electrolytes is a delicate balance. } 3 \% \text { NaCl or mannitol is administered by } \\
\text { IV to draw fluid into the vascular space for excretion. These medications need careful monitoring. } \\
\text { Urine analysis tests show the patient's fluid status via ADH production and monitoring for } \\
\text { electrolyte imbalances is necessary. } \\
\text { II) Before administering anything orally, a speech pathologist should be consulted, for patients are } \\
\text { at a high aspiration risk. An NG or OG tube may be the primary source of nutrition. The patient } \\
\text { should be on a high calorie, protein, and fiber diet. } \\
\text { III) The family must always be supported. Increased ICP often causes long term complications. } \\
\text { Families need to be told the facts of the patient's condition, so they can make informed decisions, } \\
\text { and they are kept up to date on the patient's current condition. Nurses can suggest the family to } \\
\text { external resources that would aid them in coping with their loved one's condition. }\end{array}$ & $\begin{array}{l}\text { I) Fluid and electrolyte monitoring is } \\
\text { necessary when the patient is on diuretics } \\
\text { or NaCl solution. It is also needed when } \\
\text { ICP is elevated because of the compression } \\
\text { of the hypothalamus, and thus irregular } \\
\text { ADH production. } \\
\text { II) Increased ICP causes the patients to be } \\
\text { in a hypermetabolic state, which alters the } \\
\text { nutrition requirements of the patient. } \\
\text { III) Family should be incorporated into } \\
\text { every level of patient care. }\end{array}$ \\
\hline G & $\begin{array}{l}\text { Glascow Coma } \\
\text { Scale (GCS) }\end{array}$ & $\begin{array}{l}\text { GCS assesses motor, verbal, and eye opening ability of the patient. Nurses should try to elicit the } \\
\text { best possible response from their patient, i.e. pushing down hard on patients nail bed creating pain. }\end{array}$ & $\begin{array}{l}\text { GCS is used to assess the level of } \\
\text { consciousness of the patient with increased } \\
\text { ICP. Refer to hospital protocol for how } \\
\text { often it should be completed. }\end{array}$ \\
\hline $\mathbf{H}$ & $\begin{array}{l}\text { I) Herniation } \\
\text { II) } \\
\text { Hyperventilate } \\
\text { III) } \\
\text { Hyperthermia } \\
\text { IV) Hip } \\
\text { Flexion }\end{array}$ & $\begin{array}{l}\text { I) Prevention of herniation is the top nursing priority for patients with increased ICP. The } \\
\text { Cushing's Triad is the warning sign for impending brain herniation, and observing for this reflex is } \\
\text { essential to prevent herniation. The Cushing's Triad is composed of: Hypertension with a } \\
\text { widening pulse pressure, Bradycardia, Bradypnea. } \\
\text { II) Hyperventilation must be carefully controlled, constant monitoring of } \mathrm{CPP} \text { and } \mathrm{PaCO}_{2} \text { is } \\
\text { essential. CPP must be maintained at } 60 \mathrm{mmHg} \text {. If not, the patient's condition can worsen. } \\
\text { III) Prevention of hyperthermia, and promotion of moderate hypothermia is done by giving the } \\
\text { patient cooling blankets. Maintain the body temperature between } 32-34 \text { degrees for a minimum of } \\
2 \text { days. Rewarming of the patient must be gradual. } \\
\text { IV) Nurse ensures the hips are not flexed, and that the body is in a lateral position. }\end{array}$ & $\begin{array}{l}\text { I) Herniation can cause brain death, and is } \\
\text { to be avoided. } \\
\text { II) Hyperventilation is used only when } \\
\text { other means of reducing ICP is not } \\
\text { effective. } \\
\text { III) Hypothermia is done to reduce } \\
\text { metabolic demands of the brain, and to } \\
\text { decrease the level of CO2 in the body, } \\
\text { decreasing ischemia in the brain. } \\
\text { IV) Hip flexion is never performed. }\end{array}$ \\
\hline I & $\begin{array}{l}\text { ICP } \\
\text { Monitoring }\end{array}$ & $\begin{array}{l}\text { ICP is monitored via a catheter inserted into a burr hole. The pressure is exerted on a digital } \\
\text { monitor, which the nurse monitor. }\end{array}$ & $\begin{array}{l}\text { Monitoring ICP should be done early in } \\
\text { the course of the disability, and } \\
\text { continuously when ICP is elevated, or } \\
\text { suspected to be. }\end{array}$ \\
\hline $\mathbf{J}$ & Jugular Veins & $\begin{array}{l}\text { To assess the internal jugular vein: } \\
\text { - Raise head of bed } 30-45 \text { degrees } \\
\text { - Turn patients head away from practitioner, ensure adequate lighting and find jugular pulsation } \\
\text { - Place one ruler vertically on angle of Louis, place a second ruler horizontally at 90-degrees to the } \\
\text { first ruler } \\
\text { - End of second ruler placed where jugular pulsation is seen } \\
\text { - Measure for distention } \\
\text { Normally, jugular distention is no more than } 3 \mathrm{~cm} \text {, or } 1 \text { in. }\end{array}$ & $\begin{array}{l}\text { Assessment of the internal jugular vein is } \\
\text { done to assess venous pressure, and thus } \\
\text { the ability of the cerebrovascular system to } \\
\text { drain. This is an indicator of ICP. }\end{array}$ \\
\hline $\mathbf{K}$ & $\begin{array}{l}\text { Kernig's \& } \\
\text { Brudzinski's } \\
\text { sign }\end{array}$ & $\begin{array}{l}\text { To test for Kernig's sign: } \\
\text { - Get patient to lie down with hips and knees flexed } \\
\text { - Ask patient to extend knees, if they cannot be extended past } 135 \text { degrees without pain occurring, } \\
\text { it is a positive Kernig's sign } \\
\text { To test for Brudzinski's sign: } \\
\text { - Get the patient to lie down straight } \\
\text { - Flex the patients neck, and observe for involuntary flexion of the patients knees and hips }\end{array}$ & $\begin{array}{l}\text { Kernig's \& Brudzinski sign identifies } \\
\text { whether or not someone has meningitis. If } \\
\text { meningitis is suspected, i.e. basal skull } \\
\text { fracture, Kernig's and Brudzinski's signs } \\
\text { help with the diagnosis }\end{array}$ \\
\hline $\mathbf{L}$ & $\begin{array}{l}\text { Lumbar } \\
\text { Puncture }\end{array}$ & A lumbar puncture is performed at the level of L3 to L5. & $\begin{array}{l}\text { A lumbar puncture is contraindicated in } \\
\text { patients with increased ICP, due to the risk } \\
\text { for brain herniation }\end{array}$ \\
\hline
\end{tabular}


J: Jugular Veins. The veins in the cerebrovascular venous system have no valves. ${ }^{[1]}$ Hence, gravity facilitates drainage from this system. If there is an increase in intra-abdominal or intrathoracic pressure, or there is jugular venous distention, the veins cannot adequately drain. Blood volume in the brain increases, and ICP builds. This is why elevation of the head of the bed is necessary, and why decompressing the stomach is recommended.

The jugular veins inform practitioners of the pressure in the venous system. ${ }^{[14]}$ Hence, jugular vein distention is a sign of increased pressure in the veins. To assess the jugular veins, the healthcare provider raises the head of the bed to 30-45 degrees and ensures there is adequate lighting. The nurse observes for the internal jugular vein, because it is the best indicator of venous pressure. This vein is located behind the sternocleidomastoid muscle, medial to the external jugular and lateral to the carotid artery. The patients head should be turned away from the nurse, and if the internal jugular is visible, the nurse measures it by placing a ruler vertically on the angle of Louis, and by placing another ruler horizontally at a 90-degree angle to the first ruler. The end of the second ruler should be placed where the internal jugular pulsation is seen. Normally, the jugular veins are not distended more than $3 \mathrm{~cm}$ (1 in.) above the sternal angle.

K: Kernig's and Brudzinski's Sign. Kernig's and Brudzinski's signs are indicators of meningeal irritation that is often caused by meningitis. Meningitis is the infection of the meninges of the brain. ${ }^{[15]}$ This can happen with a basal skull fracture, where CSF can come into contact with bacteria because of the openings in the skull. An increased temperature and altered LOC are manifestations of meningitis and should be monitored. Kernig's sign is elicited by having the patient supine with the hips and knees flexed. When the knees are extended in patients with meningitis, pain occurs. If the knees cannot be extended past 135 degrees, it is a positive Kernig's sign. Brudzinski's sign is elicited by positioning the patient in a supine position, and flexing the neck. Following neck flexion there will be involuntary flexion of the patient's knees and hips. Brudzinski's sign is a more sensitive indicator for meningitis than is Kernig's sign. ${ }^{[15]}$ Intracranial pressure may increase in patients with meningitis due to hydrocephalus or swelling of the brain. ${ }^{[15]}$ Thus, it is imperative that a patient positive for Kernig's and Brudzinski's signs is monitored for increased ICP as well.

L: Lumbar Puncture. Lumbar punctures (LP) are contraindicated in patients with increased ICP. An LP is performed at the level of L3 to L5, into the subarachnoid space of the spinal cord. ${ }^{[16]}$ An LP, or spinal tap, is used to obtain CSF for either examination or as a means to drain it. When a patient has increased ICP, however, performing an LP can be life-threatening. The opening in the spine provokes negative pressure, due to removal of CSF that causes decreased intraspinal pressure. The decrease in intraspinal pressure combined with the increase in intracranial pressure causes the brain to move downward, compressing the brain stem and causing possible brain herniation. The intraspinal pressure is measured by a manometer directly attached to the needle used for the lumbar puncture procedure; the pressure exerted by the CSF must not exceed $20 \mathrm{~cm} \mathrm{H}_{2} \mathrm{O}$, or lumbar puncture is contraindicated.

\section{Conclusion}

For the novice practitioner, it can be overwhelming to understand the complexities of dealing with a patient who has increased ICP. This article uses the acronym of the alphabet, A through $\mathrm{L}$, as a mnemonic to facilitate the practitioner through nursing care and management of a patient with elevated ICP. Through the use of this mnemonic, the student or the nurse can identify priorities, nursing strategies, and appropriate actions to be taken. The mnemonic is an approach to increased ICP, which is intended to facilitate the practitioner through managing the condition, and to act as tool for the nurse to recognize how to care for such a patient. Time is a critical factor when caring for patients with increased ICP, it only takes 5 minutes for irreversible brain cell death to occur. Any tool that helps increase a practitioner's response time could mean the difference between life and disability. Elevated ICP is a mosaic, and the ABC's defining this concept guide the practitioner in piecing together its complexities.

\section{Conflicts of InTERest Disclosure}

The authors declare that there is no conflict of interest.

\section{REFERENCES}

[1] March KS, Hickey JV. Intracranial hypertension: theory and management of increased intracranial pressure. In Hickey, JV, (Ed.). The clinical practice of neurological and neurosurgical nursing (Vol. 3). Philadelphia, PA: Lippincott Williams \& Wilkins. 2014.

[2] Marsh JD, Banasik JL. Acute disorders of brain function. In Cop- stead, L., and Banasik J, (Eds.). Pathophysiology (Vol. 5). St. Louis, MO: Elsevier. 2013.

[3] Gooley AM, Moniz NM, Hunter J. Management of patients with neurological dysfunction. In Paul, P., Day, R.A., and Williams, B. (Eds.). Canadian Textbook of Medical Surgical Nursing (Vol. 3). Philadelphia, PA: Wolters Kluwer. 2016. 
[4] Heart \& Stroke Foundation. Highlights of the 2015 Guidelines Update for CPR and ECC - Heart \& Stroke Foundation of Canadian Edition [Internet]. 2015. Available from: http: //www . heartandstroke.com/atf/cf /\%7B99452d8b-e7f 1-4 bd6-a57d-b136ce6c95bf \%7D/ECC $\% 20$ HIGHLIGHTS $\% 200 F \% 202$ 015\%20GUIDELINES\%20UPDATE $\% 20$ FOR $\% 20$ CPR $\% 20$ ECC_LR.PDF

[5] Banasik JL. Structure and function of the nervous system. In Copstead, L., and Banasik J, (Eds.). Pathophysiology (Vol. 5). St. Louis, MO: Elsevier. 2013.

[6] Schumann LL. Respiratory function and alterations in gas exchange. In Copstead, L., and Banasik J, (Eds.). Pathophysiology (Vol. 5). St. Louis, MO: Elsevier. 2013.

[7] Hunter J. Management of patients with neurologic trauma. In Paul, P., Day, R.A., and Williams, B. (Eds.). Canadian Textbook of Medical Surgical Nursing (Vol. 3). Philadelphia, PA: Wolters Kluwer. 2016.

[8] McLean D. Assessment and management of patients with hypertension. In Paul, P., Day, R.A., and Williams, B. (Eds.). Canadian Textbook of Medical Surgical Nursing (Vol. 3). Philadelphia, PA: Wolters Kluwer. 2016. PMid:27354985

[9] Sparke A, Voss S, Benger J. The measurement of tissue interface pressures and changes in jugular venous parameters associated with cervical immobilisation devices: a systematic review. Scandinavian Journal of Trauma, Resuscitation, \& Emergency Medicine. 2013;
21(81). PMid: 24299024 http://dx.doi.org/10.1186/1757-7 241-21-81

[10] REFERENCE MISSING. .. MCQILLAN ET AL 2002.

[11] Rock L. Management of patients with renal disorders. In Paul, P., Day, R.A., and Williams, B. (Eds.). Canadian Textbook of Medical Surgical Nursing (Vol. 3). Philadelphia, PA: Wolters Kluwer. 2016.

[12] Adams MP, Urban CQ (Eds.). Pharmacology - connections to nursing practice. 3rd ed. United States of America: Pearson. 2016.

[13] Yokobori S, Yokota H. Targeted temperature management in traumatic brain injury. Journal of Intensive Care. 2016; 4(28). PMid: 27123304 http://dx.doi.org/10.1186/s40560-016 $-0137-4$

[14] D’Amico D, Barbarito C, Twomey C, et al. Health \& physical assessment in nursing. Canadian ed. Toronto ON: Pearson Canada. 2012.

[15] Wohlgemuth JM. Management of patients with neurologic infection, autoimmune disorders, and neuropathies. In Paul, P., Day, R.A., and Williams, B. (Eds.). Canadian Textbook of Medical Surgical Nursing (Vol. 3). Philadelphia, PA: Wolters Kluwer. 2016.

[16] Skillen DL. Assessment of neurological function. In Paul, P., Day, R.A., and Williams, B. (Eds.). Canadian Textbook of Medical Surgical Nursing (Vol. 3). Philadelphia, PA: Wolters Kluwer. 2016. 